\title{
QUALIDADE DA COLHEITA E ATRIBUTOS FÍSICOS DO SOLO: IMPLICAÇÕES NO PLANEJAMENTO DA REFORMA DE POVOAMENTOS FLORESTAIS
}

\author{
Reginaldo Sérgio Pereira ${ }^{1}$, Raul Silvestre ${ }^{2}$, Mauro Eloi Nappo ${ }^{3}$, Éder Pereira Miguel ${ }^{4}$, Fabiano Emmert ${ }^{5}$
}

\section{RESUMO}

O objetivo foi avaliar os reflexos da colheita de madeira com o uso da motosserra e das propriedades físicas do solo em duas áreas destinadas à reforma de povoamentos de eucalipto. O estudo foi conduzido na Fazenda Água Limpa (FAL), pertence à Universidade de Brasília (UnB). Foram escolhidas duas áreas a serem submetidas ao processo de reforma. A área 1 (AR1) foi colhida em 2010 e a área 2 (AR2) foi colhida em 2004 e abandonada para regeneração. Na AR2 a altura dos tocos estava fora dos padrões técnicos recomendados $(<5 \mathrm{~cm})$, o que impossibilita a entrada dos implementos florestais para o preparo do solo. Foi realizado um inventário e determinado o rendimento e os custos operacionais de rebaixamento desses tocos. Tanto na $\mathrm{AR} 1$ quanto na $\mathrm{AR} 2$ os parâmetros resistência à penetração, densidade e umidade higroscópica do solo foram determinados. As amostras de solo foram caracterizadas como altamente plásticas, com comportamento argiloso laterítico. Os valores máximos de RP concentraram-se nas profundidades de solo de 25 até $35 \mathrm{~cm}$ e houve pouca variação na densidade do solo entre as duas áreas, com valores próximos a $1000 \mathrm{~kg} \mathrm{~m}^{-3}$. Na AR2 o volume de madeira desperdiçado na forma de tocos foi de aproximadamente $13,70 \mathrm{~m} / \mathrm{ha}$, sendo necessárias 16,7 horas para rebaixar um hectare, a um custo de $\mathrm{R} \$ 492,48 \mathrm{ha}^{-1}$.

Palavras-chave: custos, eucalipto, produtividade, reforma.

\section{ABSTRACT \\ HARVEST QUALITY AND SOIL PHYSICAL ATTRIBUTES: IMPLICATIONS ON THE PLANNING OF REGROWTH FOREST STANDS}

The objective of this study was to evaluate the consequences of timber harvesting with the use of chainsaws and the physical properties of soil in two regrowth eucalyptus stands. The study was conducted at the Água Limpa Farm, belonging to the University of Brasília (UnB). Two areas were chosen to undergo the regrowth process. Area 1 (AR1) was harvested in 2010 and area 2 (AR2) was harvested in 2004 and abandoned for regeneration. In AR2 the height of the stumps was outside the recommended technical standards $(<5 \mathrm{~cm})$, which prevents the entry of forest implements for soil preparation. An inventory was performed and the yield and operating costs of lowering these stumps was determined. In both the AR1 and AR2, the parameters of penetration resistance, density and hygroscopic moisture of the soil were determined. Soil samples were characterized as highly plastic with lateric clay properties. The maximum values of RP were concentrated in soil depths of 25 to $35 \mathrm{~cm}$ and there was little variation in soil density between the two areas, with values close to $1.0 \mathrm{~kg} \mathrm{~m}^{-3}$. In AR2 the amount of wood wasted in the form of stumps was approximately $13.70 \mathrm{~m}^{3}$ ha-1, requiring 16.7 hours to lower the stumps of one hectare at a cost of $\mathrm{R} \$ 492.48$ ha- 1 (one dollar equals $\mathrm{R} \$ 1.70)$.

Keywords: costs, eucalyptus, productivity, regrowth.

\section{Recebido para publicação em 12/03/2012. Aprovado em 27/03/2013.}

1 - Eng. Florestal, Prof. Adjunto, Departamento de Engenharia Florestal, UnB/Brasília-DF, reginaldosp@unb.br

2 - Eng. Florestal, Doutorando em Ciências Florestais, UnB/Brasília-DF, silvestrefloresta@yahoo.com.br

3 - Eng. Florestal, Prof. Adjunto, Departamento de Engenharia Florestal, UnB/Brasília-DF, mauronappo@yahoo.com.br

4 - Eng. Florestal, Doutorando em Ciências Florestais, UnB/Brasília-DF, edermiguel@unb.br

5 - Eng. Florestal, Doutorando em Ciências Florestais, UnB/Brasília-DF, fabianoemmert@yahoo.com.br 


\section{INTRODUÇÃO}

A melhoria da qualidade das operações de campo em áreas silvícolas pode ser obtida se houver um sistema de controle de qualidade implantado na colheita florestal. Entre os parâmetros apontados por Jacovine (2005) destacam-se a altura dos tocos (ou cepas) e o comprimento de toras. As cepas oriundas de plantios anteriores representam grande obstáculo para os plantios florestais utilizando os sistemas mecanizados.

Em relação à problemática dos tocos remanescentes de um plantio, pode-se escolher entre duas medidas de alto custo na reforma de um povoamento florestal, a destoca e o rebaixamento do toco (MORO et al., 1988) .

A primeira situação é a forma mais agressiva para um solo em uma reforma do povoamento realizada geralmente com um trator de esteira com lâmina, o que causa um grande revolvimento do solo. Esse revolvimento disponibiliza nutrientes para o crescimento inicial da muda, porém, desprotege o solo, tornando-o mais susceptível à erosão e à lixiviação dos nutrientes (GATTO et al., 2003).

O rebaixamento de tocos pode ser definido como uma operação realizada nas áreas de reforma, quando a altura ou alinhamento dos tocos dos plantios anteriores estiver comprometendo as atividades subsequentes. Essa operação visa reduzir a altura do toco deixando-o mais próximo à superfície para que as máquinas utilizadas em outras operações possam transitar mais facilmente pelo talhão. $\mathrm{O}$ toco a ser rebaixado pode ser o toco verde recém-cortado ou o toco da rotação anterior que ainda não se degradou (PAGOTTO et al., 2007).

As vantagens do rebaixamento em relação a destoca é que o primeiro mantém ou melhora as características físicas do solo, reduz as perdas de nutrientes do ecossistema, mantém ou eleva a atividade biológica e a fertilidade do solo, reduz a infestação de plantas invasoras, reduz as despesas de implantação e reforma de povoamentos florestais e aumenta a eficiência operacional das atividades de campo. Além disso, o toco como resíduo florestal pode ser usado na geração de energia de biomassa vegetal (DUBÉ, 1999).
O conhecimento das propriedades físicas do solo também é essencial para a utilização de áreas destinadas a plantios florestais. Portanto, estudos são realizados para determinar fatores que possam ser ou não significativos para algum tipo de cultura específica, assim como a extensão das áreas de plantio (GONÇALVES et al., 2002).

O solo é o componente do habitat que mais influencia o crescimento das plantas e, entre seus principais atributos, encontram-se: a textura, estrutura, temperatura, $\mathrm{pH}$, fertilidade, umidade e aqueles relacionados com o material de origem (PRITCHETT, 1979). Entre os atributos do solo, aqueles relacionados com os aspectos físicos são de extrema importância, pois dizem respeito ao desenvolvimento das plantas. Segundo Brady (1996), quanto menor a densidade do solo e a resistência à penetração das raízes, e maior a porosidade total, a macroporosidade e a disponibilidade de água, maiores são as taxas de crescimento das áreas florestais.

O grande desafio do manejo do solo consiste em identificar o equilíbrio entre estratégias e métodos silviculturais que mantenham ou elevam a produtividade a longo prazo, sem ou com mínimos impactos negativos ao ambiente (PREVEDELLO, 2008).

Segundo Neves Junior (2005), a qualidade física do solo diz respeito à capacidade do mesmo em promover ao sistema radicular das plantas condições favorável ao crescimento e desenvolvimento.

Forsythe (1967) argumenta que os principais fatores físicos de crescimento são: a disponibilidade de água e ar, temperatura e resistência que o solo oferece à penetração das raízes. $\mathrm{O}$ teor de água no solo controla a aeração, a temperatura e a impedância mecânica, os quais são afetados pela densidade do solo e distribuição do tamanho de poros. Esses fatores juntos interagem e regulam o crescimento e funcionalidade das raízes refletindo diretamente na produtividade dos cultivos (REICHERT et al., 2003). A necessidade do preparo do solo é de conhecimento do engenheiro florestal, pois no manejo o solo é um dos fatores silviculturais mais relevantes.

Os primeiros florestamentos realizados nas décadas de 60 e 70 aplicavam métodos

\section{REVENG}


convencionais de preparo do solo, como revolvimento e aplicação de produtos tóxicos nas culturas. Já na década de 80, foi introduzida a grade bedding (SUITER et al., 1980), que proporcionava maior conservação do solo e operacionalidade, pois os camalhões eram em curva de nível, causando menor revolvimento do solo e, consequentemente, menor erosão.

Outro fator implantado no final da década de 80 foi a introdução do cultivo mínimo do solo (SANCHES et al., 1995), que utiliza o subsolador para o preparo do solo, o qual penetra no solo com profundidade de até 50 centímetros. O subsolador promove uma tensão de cisalhamento no solo e esta tensão propaga-se até a superfície do solo num ângulo de $45^{\circ}$, gerando uma seção triangular de solo desadensado (RIPOLI et al., 1985; BALESTREIRE, 1987; SASAKI et al., 2002).

Assim sendo, o objetivo do trabalho foi avaliar os reflexos da colheita semimecanizada e dos atributos físicos do solo em duas áreas destinadas à reforma de povoamentos de eucalipto.

\section{MATERIAL E MÉTODOS}

O estudo foi realizado na Fazenda Água Limpa (FAL), pertence à Universidade de Brasília (UnB). A FAL possui aproximadamente 300 ha com plantios de eucalipto. São colhidos, anualmente, 10 ha e plantados em média 14 ha, sendo a destinação da madeira para a construção civil, produção de carvão vegetal, abastecimento de fornos etc. Para a realização do trabalho, foram selecionadas duas áreas de reforma de povoamento de eucalipto de, aproximadamente 2,0 hectares cada.

Foi realizada uma inspeção em campo e georreferenciadas as áreas de plantio de eucalipto a serem reformadas. Os critérios para a escolha das áreas foram: (a) ano de corte do povoamento; e (b) condições de limpeza da área.

A área 1 (AR1) foi colhida em 2010, sendo todos os critérios operacionais de corte obedecidos, inclusive altura de tocos próxima ao nível do solo; A área 2 (AR2) foi colhida em 2004, sendo a altura dos tocos deixado fora dos padrões técnicos recomendados $(<5 \mathrm{~cm})$ para a reforma de povoamentos. Ressalta-se que, na AR2 havia inúmeras brotações nos tocos. Na Figura 1 encontra-se o aspecto físico das duas áreas de estudo.

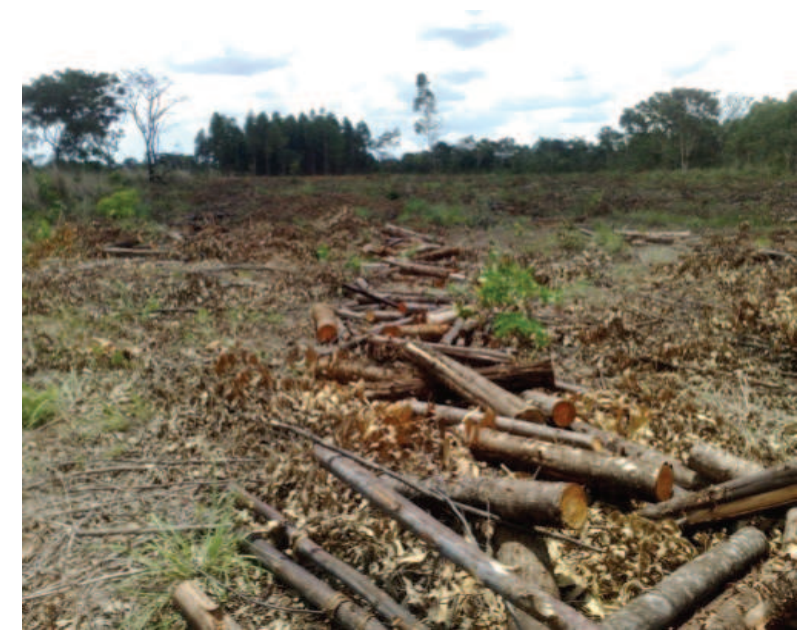

(a)

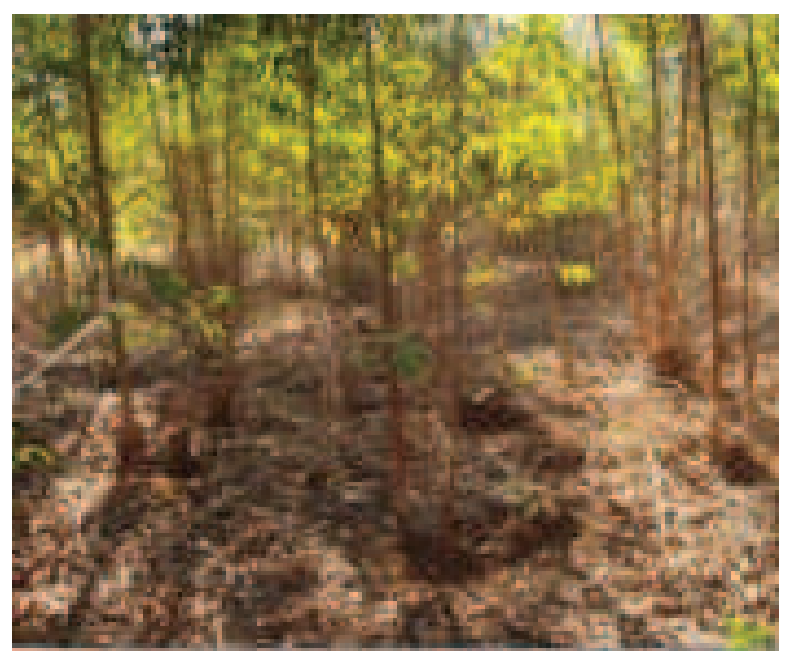

(b)

Figura 1. Áreas para reforma de povoamento: (a) AR1; e (b) AR2.

Para a determinação dos parâmetros físicos do solo foram realizadas coletas de dados de $20 \mathrm{em}$ 20 metros ao longo da maior dimensão das áreas de estudo $(200 \mathrm{~m})$ e nas extremidades superior, inferior e centro.

Para a coleta de solo foi utilizado um trado tipo holandês e coletadas amostras compostas nas profundidades de $0-10 \mathrm{~cm}$ e $10-30 \mathrm{~cm}$. Os seguintes procedimentos e determinações foram realizados no laboratório de geotecnia da UnB: (a) análise granulométrica (ABNT, 1984a); (b) consistência do solo - limite de liquidez (ABNT, 1984b) e limite de plasticidade (ABNT, 1984c); (c) massa específica dos grãos de solos (ABNT, 1984d). Os solos foram classificados pela metodologia MCT 
- Miniatura Compactada Tropical (NOGAMI; VILLIBOR, 1994) e pelo método do triângulo textural (LEMOS; SANTOS, 1996).

A densidade do solo foi determinada pelo método do anel volumétrico (EMBRAPA, 1997), nas profundidades de $0-10 \mathrm{~cm}$ e $10-30 \mathrm{~cm}$, utilizando amostras indeformadas retiradas com anel de aço de bordas cortantes com volume interno de $80,54 \mathrm{~cm}^{3}$. A amostra indeformada de solo foi seca em estufa à $\pm 105^{\circ} \mathrm{C}$, durante 48 horas, para a determinação do teor de água por meio da seguinte equação:

$U=\frac{m_{i-} m_{s}}{m_{s}} \times 100$

em que

$\mathrm{U}=$ umidade máxima do solo, em \%;

$\mathrm{mi}=$ massa de solo inicial, em gramas $(\mathrm{g})$; e

$\mathrm{ms}=$ massa de solo seco, em gramas $(\mathrm{g})$.

Utilizando-se a relação entre a massa de solo seco e o volume do anel de aço, foi calculada a densidade das amostras de solo através da seguinte expressão:

$D=\frac{m_{s}}{V}$

em que

$\mathrm{D}=$ densidade do solo, em $\mathrm{g} \mathrm{cm}^{-3}$;

$\mathrm{ms}=$ massa de solo seco, em gramas $(\mathrm{g}) ; \mathrm{e}$

$\mathrm{V}=$ volume do cilindro, $\mathrm{em}^{3}$.

Para determinação da resistência do solo à penetração, foi utilizado um penetrômetro de impacto, modelo IAA/Planalsucar. Foram analisadas as profundidades de 0 até $50 \mathrm{~cm}$, fazendo-se as anotações a cada $5 \mathrm{~cm}$ de penetração da ponteira do penetrômetro. Os resultados obtidos em impactos.dm- ${ }^{-1}$ foram convertidos para resistência do solo à penetração (RP), por meio da seguinte equação proposta por Stolf (1991), modificada para a altura de queda de 19,6 cm e área da ponteira de $1,27 \mathrm{~cm}^{2}$ :

$R P=5,67+3,43 N$

em que
$\mathrm{RP}=$ resistência do solo à penetração, em kgf.cm ${ }^{-2} ; \mathrm{e}$ $\mathrm{N}=$ número de impactos para atingir 5 centímetros de profundidade no solo.

Os valores de RP, em $\mathrm{g} \mathrm{cm}^{-3}$, foram convertidos para $\mathrm{MPa}$, multiplicando-se o resultado obtido pela constante 0,098 . Para obtenção da umidade gravimétrica, concomitante às medidas de RP, foram coletadas amostras de solo nas camadas $0-10 \mathrm{~cm}$ e $10-30 \mathrm{~cm}$.

Os dados de densidade e resistência do solo à penetração foram analisados com o auxílio do programa SPSS Statistics versão 17.0; utilizou-se o teste $\mathrm{F}$, estabelecido um nível de probabilidade de $95 \%$ de confiabilidade.

Para a avaliação da qualidade da colheita florestal foram determinados o volume total de cada toco da área 2. Para tanto, foram lançadas dez parcelas de 0,01 ha $(10 \times 10 \mathrm{~m})$ distribuídas sistematicamente. Foram medidos a altura, a partir da superfície do solo, e o diâmetro de todos os tocos remanescentes dentro de cada parcela. $\mathrm{O}$ volume de cada toco foi estimado pelo método de Huber que prevê a medição do diâmetro ou da circunferência na metade da seção da tora (MACHADO; FIGUEIREDO FILHO, 2003), de acordo com a seguinte expressão:

$V=g m x l$

em que

$V=$ volume do toco $\left(\mathrm{m}^{3}\right)$;

$g m=$ área seccional média $\left(\mathrm{m}^{2}\right)$; e

$l=$ altura do toco $(\mathrm{m})$.

Para a determinação da área seccional média (gm), o diâmetro (D) foi mensurado no meio do toco com auxílio de uma suta, e empregou-se a seguinte expressão:

$g m=\pi x D^{2} / 40.000$

em que

$\mathrm{D}=$ diâmetro do toco $(\mathrm{m})$. 
Avaliou-se também o rendimento e os custos operacionais do rebaixamento de toco com motosserra. Foi realizado um estudo de tempos e movimentos, onde o tempo dos elementos do ciclo operacional, registrados com o auxílio de um cronômetro sexagesimal, marca ULTRAK 480, foram os seguintes: (a) tempo efetivamente de trabalho (rebaixamento com motosserra e deslocamento ao próximo toco); e (b) tempo de interrupções (reabastecimento, afiação da corrente e problemas técnicos). A operação foi realizada em sistema de $1+1$, onde um operador foi à frente realizando a limpeza ao redor do toco e o outro operador realizava o rebaixamento com motosserra.

Através da relação entre o volume total dos tocos $\left(\mathrm{m}^{3}\right)$ e do número de horas efetivamente trabalhadas gastas (he) na operação de rebaixamento, foi obtida a produtividade $\left(\mathrm{m}^{3}\right.$ he $\left.{ }^{-1}\right)$ da operação na área total.

Para a determinação dos custos operacionais utilizou-se o método descrito por MIYATA (1980), onde o custo operacional é dividido em custos fixos, variáveis e de administração, expressos em reais por hora efetiva de trabalho $\left(\mathrm{R} \$ \mathrm{he}^{-1}\right)$. O custo de produção da motosserra $\left(\mathrm{R} \$ \mathrm{~m}^{-3}\right)$ foi obtido pela divisão dos custos operacionais totais $\left(\mathrm{R} \$ \mathrm{he}^{-1}\right)$ pela produtividade do rebaixamento de toco (toco $h^{-1}$ ) da máquina.

As seguintes premissas foram adotadas para o cálculo dos custos operacionais: (a) valor de aquisição da motosserra ( $\mathrm{R} \$ 2.800,00)$; (b) valor de revenda (R\$280,00); (c) taxas de juros $(12 \%$ ao ano) e seguros (4 \% ao ano); (d) vida útil estimada (5 anos); (e) horas de tralhado ( 8 horas $\mathrm{dia}^{-1}$, durante 300 dias ano-1); (f) combustível (R $\$ 3,20 \mathrm{~L}^{-1} \mathrm{e}$ consumo de 1,77 $\left.\mathrm{Lh}^{-1}\right)$; (g) óleo lubrificante ( $\mathrm{R} \$$ 2,15 $\mathrm{L}^{-1}$ e consumo de $\left.0,99 \mathrm{Lh}^{-1}\right)$; (h) manutenção e reparos (R\$ 1,25 h-1); (i) EPI's $\left(R \$ 0,28 \mathrm{~h}^{-1}\right)$; (j) materiais auxiliares - sabre, corrente e limas $(\mathrm{R} \$$ $0,32 \mathrm{~h}^{-1}$ ); e (k) mão de obra operacional (salário do operador de $\mathrm{R} \$ 935,00$ mês $^{-1}+$ encargos e despesas socais).

\section{RESULTADOS E DISCUSSÃO}

No Quadro 1 encontram-se os resultados dos ensaios de caracterização e classificação das amostras de solo. As áreas, AR1 e AR2 estão localizadas no mesmo sítio, sendo ambos os solos classificados pelo Sistema Brasileiro de Classificação de Solos (EMBRAPA, 2006) como Latossolo Vermelho-Amarelo distrófico típico. O horizonte superficial é A moderado, com textura muito argilosa, havendo predominância da fração argila, com variação de 60,6 a $66,2 \%$ (camada de $0-10 \mathrm{~cm}$ ) e de 69,0 a 72,0 \% (camada de 10 $30 \mathrm{~cm}$ ). As porcentagens de areia variaram de 18,5 a $23,9 \%$ (camada de $0-10 \mathrm{~cm}$ ) e de 14,5 a $15,8 \%$ (camada de $10-30 \mathrm{~cm}$ ). Na fração silte a variação foi de 15,1 a $15,8 \%$ (camada de $0-10 \mathrm{~cm}$ ) e de 12,2 a $16,2 \%$ (camada de $10-30 \mathrm{~cm}$ ).

Quadro 1. Índices físicos e classificação dos solos

\begin{tabular}{lcc}
\hline \multirow{2}{*}{ Propriedade analisada } & \multicolumn{2}{c}{ Camada de Solo } \\
\cline { 2 - 3 } Argila $(\Phi \leq 0,002 \mathrm{~mm})$ & $0-10 \mathrm{~cm}$ & $10-30 \mathrm{~cm}$ \\
Silte $(0,002<\Phi \leq 0,06 \mathrm{~mm})$ & 64,17 & 70,60 \\
Areia $(0,06<\Phi \leq 2 \mathrm{~mm})$ & 15,47 & 13,93 \\
LL $(\%)$ & 20,33 & 15,37 \\
LP $(\%)$ & 56,93 & 54,13 \\
IP $(\%)$ & 37,33 & 35,23 \\
$\gamma \mathrm{S}\left(\mathrm{g}\right.$ cm $\left.{ }^{-3}\right)$ & 19,60 & 18,87 \\
Classificação MCT & 2,63 & 2,66 \\
Classificação Textural & LG' & LG' \\
\hline
\end{tabular}

Em que: LL - limite de liquidez; LP - limite de plasticidade; IP - índice de plasticidade; $\gamma \mathrm{s}$ - massa específica dos grãos. 
Os limites de liquidez (LL) e de plasticidade (LP) obtidos foram altos, variando de 52,7 a 59,6\% e de 34,7 a $38,0 \%$, respectivamente. Estes valores refletiram no alto valor do Índice de Plasticidade (IP), que variou de 17,6 a $22 \%$. Segundo Caputo (1988) os solos com IP superior a $15 \%$ são considerados altamente plásticos.

Observou-se também que nas amostras de solo de $0-10 \mathrm{~cm}$ a massa específica dos grãos $(\gamma \mathrm{s})$ foi ligeiramente menor que as mesmas amostras na profundidade 10-30 cm. Entretanto, esses valores estão abaixo do encontrado para solos no Brasil, possuindo minerais leves (KIEHL, 1979). Costa (2004), porém, mencionou que nos solos minerais a densidade real situa-se em torno de $2,65 \mathrm{~g} \mathrm{~cm}^{-3}$, mas pode ser inferior a isto no caso de horizontes com teor de matéria orgânica relativamente alta, dado que a matéria orgânica possui densidade real menor que as partículas minerais.
Com relação à classificação dos solos, pela metodologia MCT, todas as amostras foram caracterizadas como altamente plásticas, com comportamento argiloso laterítico (LG'), pela alta contração observada; e pelo método do triângulo textural foram caracterizadas como muito argilosas, sem distinção em profundidade.

$\mathrm{Na}$ Figura 2 encontram-se os resultados da resistência à penetração (RP) dos solos das áreas de estudo e a comparação, pelo teste $\mathrm{F}$, dos dados obtidos para cada área. Os valores de RP aumentaram gradativamente em função de maior profundidade no solo até a camada de $30-35 \mathrm{~cm}$ (AR1) e $25-30 \mathrm{~cm}$ (AR2). A partir desses pontos, foram observados decréscimos nos valores da resistência, até a camada de $50-55 \mathrm{~cm}$, em ambas as áreas. Resck (2005) relatou que a RP aumenta com a profundidade do solo no Cerrado.

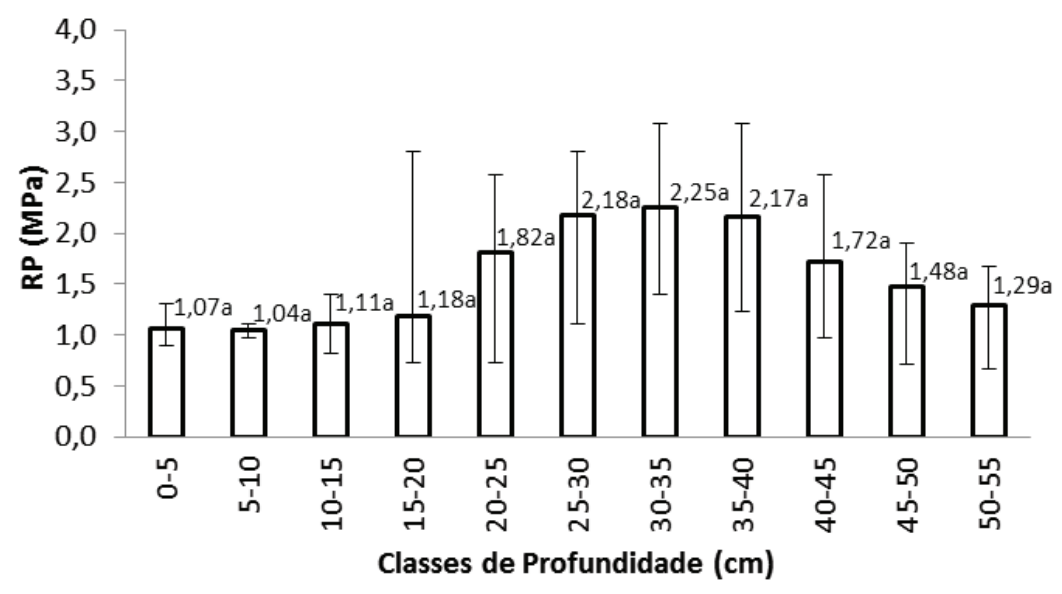

AR1

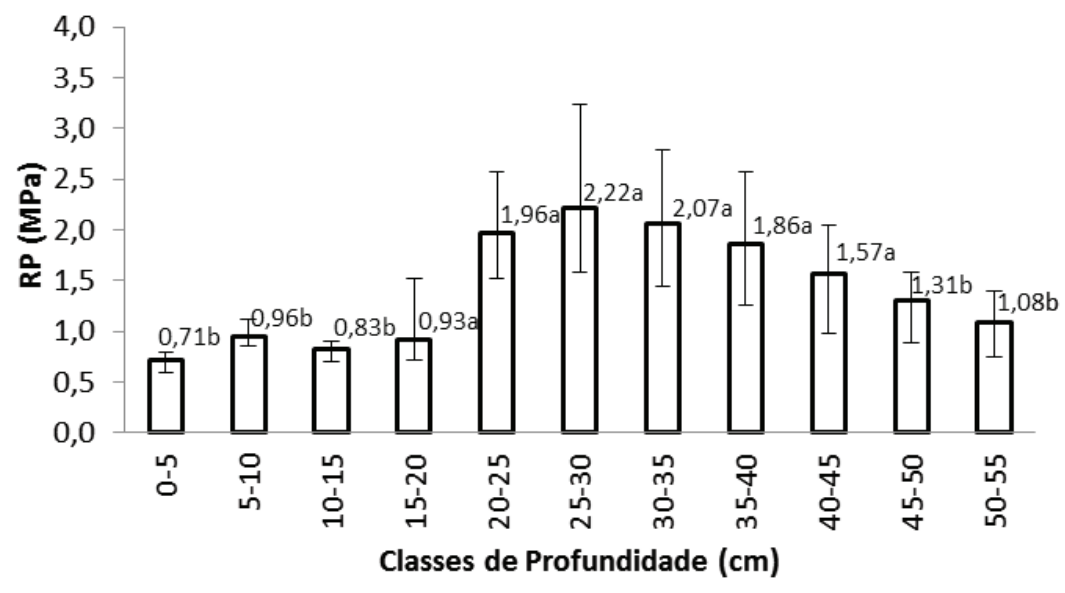

AR2

Figura 2. Valores médios, mínimos e máximos de resistência à penetração do solo das áreas AR1 e AR2 em função da profundidade do solo. Médias seguidas pela mesma letra, para a mesma profundidade das áreas de estudo, não diferem estatisticamente ao nível de $5 \%$ de significância. 
Os valores máximos de RP observados na AR1 e na AR2 foram de 3,08 MPa (camadas de solo de 30$35 \mathrm{~cm}$ e $35-40 \mathrm{~cm}$ ) e 3,24 MPa (camada de solo de $25-30 \mathrm{~cm})$, respectivamente, sendo os demais valores inferiores a 3 MPa. Segundo Zou et al., (2000), valores de RP superiores a 3 MPa são considerados limitantes ao desenvolvimento das espécies florestais. Pinheiro (2008) observou valores de RP em Cambissolo no Cerrado menores que $3 \mathrm{MPa}$. Morais (2009), avaliando a RP em Latossolo em Cerrado submetido a distúrbios antrópicos, também não observou valores de RP superiores a $3 \mathrm{MPa}$.

Não houve diferença significativa ao nível de $5 \%$ de probabilidade entre as duas áreas da camada de 15-20 até a camada de 40-45 $\mathrm{cm}$. Nas demais camadas houve significância, com tendência a maiores valores de RP para AR1, devido ao fato de maior tempo de exposição do solo da AR2 às intempéries climáticas e também à regeneração da vegetação por brotações de tocos e raízes observada na AR2.
No Quadro 2 encontram-se os resultados para a densidade e umidade dos solos. Os valores médios de densidade oscilaram pouco em relação à profundidade do solo e entre as áreas de estudo, ficando na faixa de 900 até $1050 \mathrm{~kg} \mathrm{~m}^{-3}$, com ligeira tendência a maiores valores para a área 2; para esse parâmetro físico do solo observou-se diferença significativa entre as duas áreas somente na camada de 0-10 $\mathrm{cm}$ de profundidade.

Quanto ao teor de água dos solos, notou-se também pouca variação entre os valores obtidos para as duas áreas e entre as profundidades do solo. A discrepância de valores obtidos foram de 24,94 \% a $31,54 \%$, que podem estar associadas à época de amostragem e ao período do dia em que foi coletada a amostra. Solos com baixos teores de água têm maior resistência à compactação, devido a sua maior capacidade de suporte de carga (KONDO et al., 1999). Seixas (2000) observou que o aumento do teor de água do solo resultou em redução da densidade do mesmo, causando destruição na estrutura do solo.

Quadro 2. Valores de densidade do solo $\left(\mathrm{kg} \mathrm{m}^{-3}\right)$ e umidade higroscópica (\%) encontrados para as áreas AR1 e AR2

\begin{tabular}{|c|c|c|c|c|c|c|}
\hline \multicolumn{7}{|c|}{ AR1 } \\
\hline \multirow{2}{*}{ Profundidade $(\mathrm{cm})$} & \multicolumn{3}{|c|}{ Densidade $\left(\mathrm{kg} \mathrm{m}^{-3}\right)$} & \multicolumn{3}{|c|}{ Umidade (\%) } \\
\hline & Mínimo & Médio & Máximo & Mínimo & Médio & Máximo \\
\hline $0-10$ & 820 & 900 & 1000 & 28,28 & 29,87 & 31,54 \\
\hline $10-30$ & 1010 & 1040 & 1100 & 25,71 & 28,66 & 30,60 \\
\hline \multicolumn{7}{|c|}{ AR2 } \\
\hline \multirow{2}{*}{ Profundidade $(\mathrm{cm})$} & \multicolumn{3}{|c|}{ Densidade $\left(\mathrm{kg} \mathrm{m}^{-3}\right)$} & \multicolumn{3}{|c|}{ Umidade (\%) } \\
\hline & Mínimo & Médio & Máximo & Mínimo & Médio & Máximo \\
\hline $0-10$ & 910 & 990 & 1060 & 24,94 & 27,91 & 34,92 \\
\hline $10-30$ & 860 & 1050 & 1230 & 27,29 & 28,89 & 30,05 \\
\hline
\end{tabular}

Quadro 3. Atributos dendrométricos dos tocos amostrados na área 2

\begin{tabular}{cccc}
\hline Parâmetro & Altura $(\mathrm{m})$ & Área transversal $\left(\mathrm{m}^{2}\right)$ & Volume $\left(\mathrm{m}^{3}\right)$ \\
\hline Valor Mínimo & 0,04 & 0,0003 & 0,0001 \\
Valor Médio & 0,21 & 0,0201 & 0,0053 \\
Valor Máximo & 1,04 & 0,2922 & 0,1388 \\
CV (\%) & 13,65 & 169,65 & 243,40 \\
Valor Médio Por Parcela & - & 0,6472 & 0,1693 \\
Valor Médio Por Hectare & - & 64,7235 & 13,5919 \\
\hline
\end{tabular}


As variáveis dendrométricas da AR2 encontram-se no Quadro 3, onde são apresentados valores mínimos, médios e máximos, assim como o coeficiente de variação e os valores totais dos atributos, área basal $\left(\mathrm{m}^{2}\right)$ e volume $\left(\mathrm{m}^{3}\right)$ dos tocos.

No total, 321 tocos foram inventariados nas dez parcelas lançadas. Os tocos remanescentes apresentaram uma variabilidade, em termos de volume e área basal, muito grande entre eles, como pode ser constatado através do coeficiente de variação em percentagem (Quadro 3).

Os dados de volume remanescente por hectare no povoamento na AR2 foram elevados $(13,5919$ $\mathrm{m}^{3} \mathrm{ha}^{-1}$ ), conforme explicitado no Quadro 3 . Este volume esta relacionado diretamente com a altura em que as árvores foram cortadas. Segundo Sant'Anna (2008), a altura ideal de corte deve estar compreendida nas proximidades de 0,05 metros em relação ao nível do solo, valor este negligenciado na área estudada, a qual apresentou valor médio da altura do toco de aproximadamente 0,21 metros.

A altura encontrada dos tocos na área proporcionou a elevação do volume remanescente dos tocos por hectare de aproximadamente 3,2363 $\mathrm{m}^{3}$ para $13,5919 \mathrm{~m}^{3}$, ocasionando um aumento no desperdício na ordem de $10,3556 \mathrm{~m}^{3} \mathrm{ha}^{-1}$.

Por meio da Figura 3 pode-se observar que a distribuição em intervalos de classe dos tocos não obedece a uma distribuição normal, resultado este contrário ao esperado, haja vista que em povoamentos florestais a distribuição horizontal (diamétrica) tende a normalidade.

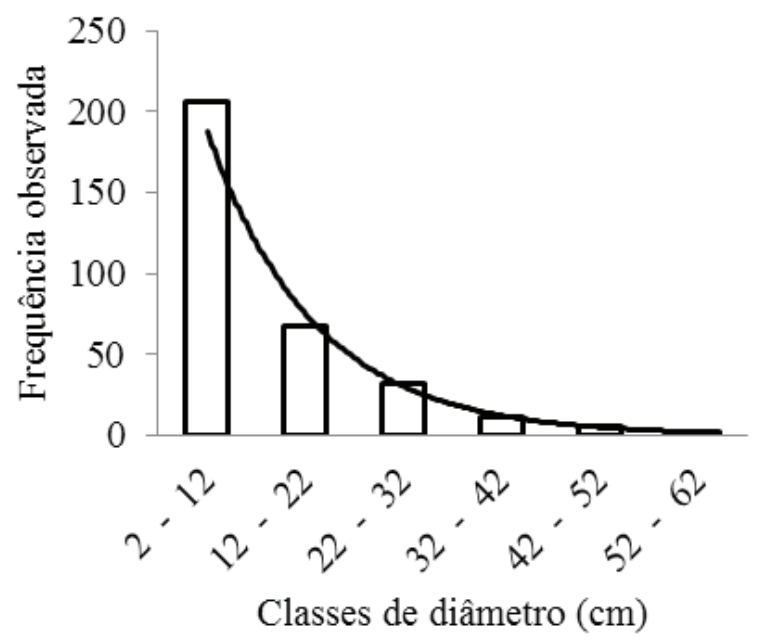

Figura 3. Distribuição em classes diamétricas dos tocos na área 2.

Os resultados apresentados na Figura 3 podem ser explicados principalmente pelos seguintes fatores: a área ter sido colhida várias vezes e em várias rotações; alta regeneração por semente e por isso não tem um espaçamento definido; ocorrência de competição com outras plantas (nativas e exóticas); e qualidade genética das mudas serem baixas.

A eficiência operacional do rebaixamento de toco na AR2 foi de $66,03 \%$, conforme apresentado no Quadro 4. Devido à discrepância dos valores de circunferência encontrados para os tocos presentes na AR2, chegou-se ao rendimento operacional de aproximadamente 193 tocos rebaixados por hora de trabalho com a motosserra. Seriam necessárias 16,7 horas para fazer um hectare, considerando-se apenas um operador de motosserra e as condições do trabalho. As causas de interrupções foram as paradas técnicas, abastecimento, afiação e lubrificação da corrente da motosserra.

Alguns estudos sobre operação de rebaixamento de toco podem ser citados: (a) Pagotto et al., (2007) utilizando trator Dinapac $236 \mathrm{cv}$, adaptado com rebaixador EcoPlantar tipo ralador horizontal, obtiveram uma eficiência operacional de 81,5\% e capacidade média de 5,2 h ha-1; (b) Moro et al., (1988) estudara as alternativas lâmina KG e rebaixador BP 500, obtendo, respectivamente, rendimento operacional de $3,3 \mathrm{~h} \mathrm{ha}^{-1}$ e 7,0 h ha-1; (c) Seixas et al., (1990) avaliando o equipamento BET $\mathrm{F} 21$, encontrara rendimento operacional de 1,63 h $\mathrm{ha}^{-1}$, enquanto para a motosserra, o rendimento em h ha ${ }^{-1}$ foi de 14,4; e (d) Lemos (2006) apresentou os rendimentos operacionais de $19,5 \mathrm{~h} \mathrm{ha}^{-1}$ e 2,5 h $\mathrm{ha}^{-1}$, respectivamente, para uma motosserra e rebaixador EcoPlantar.

O custo operacional (Quadro 4) total da operação de rebaixamento de toco foi de $\mathrm{R} \$ 29,49$ he $^{-1}$ (hora efetiva de trabalho) sendo $1,59 \%$ referente a custos fixos (depreciação, juros e seguros), 90,17 $\%$ referente a custos variáveis e $8,24 \%$ ao custo de administração (supervisão e escritório). O custo de mão de obra operacional contribui com a maior parcela dos custos variáveis $(54,68 \%)$.

Considerando que foram avaliados 321 tocos em uma área de 0,1 ha, chegou-se ao custo total ( $\mathrm{R} \$$ ha $^{-1}$ ) de 492,48. Lemos (2006) estimou entre 300,00 e 400,00 R\$ ha-1 o custo total para rebaixamento de toco para uma motosserra na empresa Suzano Papel e Celulose. Na mesma empresa o custo com rebaixador EcoPlantar foi de $\mathrm{R} \$ 500,00 \mathrm{ha}^{-1} \mathrm{e}$ com rala tocos de $\mathrm{R} \$ 480,00 \mathrm{ha}^{-1}$. Ressalta-se que o volume dos tocos era bem superior ao da AR2, pois eram referentes a florestas de eucalipto com produtividade superior a $380 \mathrm{~m}^{3} \mathrm{ha}^{-1}$ (7 anos). 
Quadro 3. Rendimento e custos da operação de rebaixamento de toco na AR2

\begin{tabular}{|c|c|c|c|c|c|c|c|c|c|}
\hline \multicolumn{10}{|c|}{ Avaliação Técnica } \\
\hline \multicolumn{6}{|c|}{ Tempo (minutos) } & \multirow{2}{*}{$\begin{array}{l}\text { Rendimento } \\
\text { (tocos/hora) }\end{array}$} & \multirow{2}{*}{\multicolumn{3}{|c|}{ Eficiência Operacional (\%) }} \\
\hline Efetivo & \multicolumn{2}{|c|}{ Interrupções } & \multicolumn{3}{|c|}{ Total } & & & & \\
\hline 66,03 & & & & 100 & & 192,6 & \multicolumn{3}{|c|}{66,03} \\
\hline \multicolumn{10}{|c|}{ Avaliação Econômica } \\
\hline \multicolumn{8}{|c|}{ Custo Operacional $\left(\mathrm{R} \$ \mathrm{he}^{-1}\right)$} & \multirow{5}{*}{$\begin{array}{l}\text { Custo de } \\
\text { Produção } \\
\left(\mathrm{R} \$ \text { toco }^{-1}\right)\end{array}$} & \multirow{5}{*}{$\begin{array}{c}\text { Custo } \\
\text { Total } \\
\left(\mathrm{R} \$ \mathrm{ha}^{-1}\right)\end{array}$} \\
\hline Fixo & & & & Variáve & & & $\mathrm{Ad}$ & & \\
\hline $\mathrm{Dp} \quad \mathrm{JS}$ & $\mathrm{Co}$ & $\mathrm{Ol}$ & MR & EPI & $\mathrm{Ma}$ & Mo & Ad & & \\
\hline $0,30 \quad 0,17$ & 5,66 & 3,62 & 1,25 & 0,28 & 0,32 & $14,54 \quad 0,92$ & \multirow{2}{*}{2,43} & & \\
\hline 0,47 & & & & 26,59 & & & & & \\
\hline TOTAL & \multicolumn{6}{|c|}{29,49} & & 0,23 & 492,48 \\
\hline
\end{tabular}

\section{CONCLUSÕES}

- As amostras de solo foram caracterizadas como altamente plásticas, com comportamento argiloso laterítico;

- Os valores máximos de RP concentraram-se nas profundidades de solo de 25 até $35 \mathrm{~cm}$ e houve pouca variação na densidade do solo entre as duas áreas, com valores próximos a $1000 \mathrm{~kg} \mathrm{~m}^{-3}$;

- Na AR2 o volume de madeira desperdiçado na forma de tocos foi de aproximadamente 13,70 $\mathrm{m}^{3} \mathrm{ha}^{-1}$, sendo necessárias 16,7 horas para rebaixar um hectare, a um custo de R $\$ 492,48 \mathrm{ha}^{-1}$.

\section{REFERÊNCIAS BIBLIOGRÁFICAS}

ASSOCIAÇÃO BRASILEIRA DE NORMAS TÉCNICAS. NBR 7181/84 : Solo: Análise Granulométrica: Procedimento. Rio de Janeiro, 1984a. 13p.

ASSOCIAÇÃO BRASILEIRA DE NORMAS TÉCNICAS. NBR 6459/84: Solo: Determinação do Limite de Liquidez. Rio de Janeiro, 1984b. 6p.

ASSOCIAÇÃO BRASILEIRA DE NORMAS TÉCNICAS. NBR 7180/84: Solo: Determinação do Limite de Plasticidade. Rio de Janeiro, ABNT, 1984c. 3p.
ASSOCIAÇÃO BRASILEIRA DE NORMAS TÉCNICAS. NBR 6508/84: Solo: Determinação da massa específica dos grãos. Rio de Janeiro, 1984d. 6p.

BALASTREIRE, L.A. Máquinas Agrícolas. São Paulo, Ed. Manole, 1987. 310p.

BRADY, N.C. The nature and properties of soils. 11. ed. Upper Saddle River: Prentice Hall, 1996. 225p.

CAPUTO, H.P. Mecânica dos solos e suas aplicações fundamentais. 6. ed. Rio de Janeiro: livros técnicos e científicos, 1988, v.1. 498p.

COSTA, J.B. Caracterização e constituição do solo. Lisboa: Fundação CalousteGulbenkian. 7 ed., 527p., 2004.

EMPRESA BRASILEIRA DE PESQUISA AGROPECUÁRIA (EMBRAPA). Manual de métodos de análises de solos. 2.ed. Rio de Janeiro, 1997. 412p.

EMPRESA BRASILEIRA DE PESQUISA AGROPECUÁRIA (EMBRAPA). Sistema brasileiro de classificação de solos. 2. ed. Rio de Janeiro: Embrapa Solos, 2006. 306p. 
DUBÉ, F. Estudos técnicos e econômicos de sistemas agroflorestais com Eucalyptus sp. no noroeste do Estado de Minas Gerais: $O$ caso da Companhia Mineira de Metais. 1999. 146f. Dissertação (Mestrado em Ciência Florestal). Universidade Federal de Viçosa, Viçosa, 1999.

FORSYTHE, W.M. Lãs propriedades físicas, los factores físicos de crescimento y la productividad del suelo. Fitotecnia Latino Americana, v.4, p.165-176, 1967.

GATTO,A.; BARROS, N.F.; NOVAIS, R.F.; COSTA, L.M.; NEVES, J.C.L. Efeito do método de preparo do solo, em áreas de reforma, nas suas características, na composição mineral e na produtividade de plantações de Eucalyptus gradis. Revista Árvore, Viçosa, MG, v.27, p.635-645, 2003.

INSTITUTO BRASILEIRO DE GEOGRAFIA E ESTATÍSTICA (IBGE). Manual técnico de pedologia. 2. ed. Rio de Janeiro, 2005.

GONÇALVES, J. L. M.; STAPE, J. L. Conservação e cultivo de solos para plantações florestais. Piracicaba: IPEF, 2002. 498p.

JACOVINE, L.A.G.; MACHADO, C.C.; SOUZA, A.P.; LEITE, H.G.; MINETTI, L.J.; Avaliação de qualidade operacional em cinco subsistemas de colheita florestal. Revista Árvore, Viçosa, MG, v.29, no.3, p.391-400, Viçosa, 2005.

KIEHL, E.J. Manual de edafologia: relações soloplanta. São Paulo: CERES, 262p, 1979.

KONDO, M.K.; DIAS JUNIOR, M.S. Compressibilidade de três Latossolos em função da umidade e uso. Revista Brasileira de Ciência do Solo, n.23, p.211-218, 1999.

LEMOS, A.V. Suzano: técnicas de plantio e manejo do Eucalyptus. Palestra... In: I SIMPÓSIO DE TÉCNICAS DE PLANTIO E MANEJO DE EUCALYPTUS PARA USO MÚLTIPLO. ESALQ, São Paulo, 25 a 27 de outubro de 2006.
LEMOS, R.C.; SANTOS, R.D. Manual de descrição e coleta de solo no campo. Campinas, SP: SBCS, 83p, 1996.

MACHADO, A.M. \& FILHO, A.F. Dendrometria. Curitiba: A Figueiredo Filho, 2003. 309p.

MIYATA, O.P. Custo operacional de máquinas utilizadas na exploração e transporte da cultura do eucalipto. Informe Agropecuário, Belo Horizonte, n.141, p.24-30, 1980.

MORAIS, F. M. Análise de atributos da vegetação e do solo em cerrado sensu stricto, 20 anos após distúrbios antrópicos. Brasília, DF, 2009. 99f. Dissertação (Mestrado em Ciências Florestais) Universidade de Brasília, 2009.

MORO, L. et al. Rebaixamento de tocos de eucaliptos. Circular técnica. IPEF, Piracicaba, (165). dez.1988.

NEVES JÚNIOR, A.F. Avaliação da qualidade física de solos em pastagens degradadas na Amazônia. Piracicaba, SP, 2005. Dissertação (Mestrado em Agronomia) - ESALQ, 2005.

NOGAMI, J.S.; VILLIBOR, D.F. Identificação expedita dos grupos da classificação MCT para solos tropicais. In: X Congresso Brasileiro de Mecânica dos Solos e Engenharia de Fundações. Anais... Foz do Iguaçu, Paraná, v.r, p.1293-1300, 1994.

PAGOTTO, L.O.; STAPE, J.L.; MENEGOL, O.; ROCHA, J.C. Avaliação do desempenho operacional e da logística das atividades silviculturais da Aracruz Celulose S.A. 2007. 85f. Estágio Profissionalizante em Engenharia Florestal. Universidade de São Paulo, Escola Superior de Agricultura "Luiz de Queiroz".

PINHEIRO, C.Q. Avaliação da recuperação da cascalheira do Aeroporto Internacional de Brasília: fatores edáficos, florísticos e ecológicos. Brasília, DF, 2008. 84f. Dissertação (Mestrado em Ciências Florestais) - Universidade de Brasília, 2008. 
PREVEDELLO, J. Preparo do solo e crescimento inicial de Eucalyptus grandis Hill ex Maiden. em argissolo. Santa Maria - Brasil, UFSM, Centro de ciências rurais, 2008.

PRITCHETT, W.L. Properties and management of forest soils. New York: J. Wiley, 1979. 500p.

REICHERT, J.M.; REINERT, D.J.; BRAIDA, J.A. Qualidade dos solos e sustentabilidade de sistemas agrícolas. Revista Ciência \& Ambiente, v.27, n.2, p.29-48, jul./dez. 2003.

RESCK, B.S. Efeito dos sistemas de manejo na dinâmica de água e no grau de compactação do solo na Bacia Hidrográfica do Córrego Taguara - DF. Brasília, DF, 2005. 121f. Dissertação (Mestrado em Ciências Agrárias) - Universidade de Brasília.

RÍPOLI, T.C.; MIALHE, L.G. \& NAKAMURA, R.T. Subsolagem e Subsoladores. Piracicaba: Centro Acadêmico Luiz de Queiroz - Departamento Editorial, 1985. 34p.

SANCHES, O.A.; YONEZAWA, J.T. \& ZEN, S. Evolução do cultivo mínimo em reflorestamento na Cia. Suzano de Papel e Celulose. In: Seminário sobre cultivo mínimo em florestas, 1, Curitiba - Brasil, 1995. Anais... Curituba - Brasil, CNPFloresta/IPEF/UNESP/SIF/FUPEF, 1995. p. $140-147$.

SANT'ANNA, C.M. Corte florestal. In: MACHADO, C.C. Colheita florestal. 2.ed. Viçosa,
MG: Universidade Federal de Viçosa, 2008. p.55-88.

SASAKI, C.M.; BENTIVENHA, S.R.P. \& GOLÇALVES, J.L.M. \& Stape, J.L. Eds. Conservação e cultivo de solos para plantações florestais. Piracicaba, IPEF, 2002. p.393 - 407.

SEIXAS, F. Implicações da colheita mecanizada sobre o preparo do solo em áreas de reforma florestal. In: Seminário sobre métodos e equipamentos de preparo do solo para plantio de florestas, 2000, Piracicaba. Anais... Piracicaba : IPEF, 2000. p.35-49.

SEIXAS, F. et al. Teste de implemento para rebaixamento de tocos em áreas de reforma de povoamentos de eucalipto. Circular técnica. IPEF, Piracicaba, (173). jun. 1990.

STOLF, R. Teoria e teste experimental de fórmulas de transformação dos dados de penetrômetro de impacto em resistência do solo. Revista Brasileira de Ciência do Solo, v.15, n.3, p.229-235, 1991.

SUITER, W.; REZENDE, G.C.; MENDES, C.J.; CASTRO, P.F. Efeitos de diferentes métodos de preparo de solo sobre o desenvolvimento de Eucalyptus grandis plantado em solos com camadas de impedimento. Circular Técnica IPEF, n.90, p.1-9, fev, 1980.

ZOU, C.; SANDS, R.; BUCHAN, G.; HUDSON, I. Least limiting water range: a potencial indicator of physical quality of forest soils. Australian Journal of Soil Research, v.38, p.947-958, 2000. 